\title{
Measuring Sustainability of Individual Tourist Behavior
}

Ralf Buckley

Theoretical frameworks for sustainable tourism include individual tourists (Juvan and Dolnicar 2016) as well as tourism enterprises (Buckley 2012). Individual tourist behaviors affect environmental outcomes at all scales, from local recreational impacts in parks to global resource consumption and greenhouse gas emissions (Gössling and Peeters 2015). Here I argue that attempts to measure the sustainable behaviors of individual tourists have been severely lacking in rigor, and a much more rigorous approach is therefore required.

Criteria used to assess the sustainability of tourist behavior have been so weak as to be largely meaningless. A meta-analysis of 21 studies (Juvan and Dolnicar 2016) identified nine previously published criteria referring only to individual psychology. These criteria were as follows: emancipated, new, post-Fordist, green, caring, conserving, responsible, true, and friendly. The same study also identified 16 previously published criteria that were so vague that compliance means little. These were awareness, impact minimization, self-audit, independence, boycotts, staying away or staying home, traveling less, resource conservation, cultural respect, care, engagement, paying extra, buying local, biospheric values, codes of conduct, environmentally friendly. None of these 21 studies included stronger criteria, such as positive contributions to conservation (Buckley 2012).

There is also a major caveat on accuracy. Sustainability of individual tourists is commonly assessed from self-reported behaviors, but self-reports are highly unreliable (Littlefair and Buckley 2008; Juvan and Dolnicar 2016). Tourists and tour operators adopt ecologically unsustainable behaviors, even where they know that they are (a) breaching legal requirements, and (b) watched by researchers or government-appointed regulatory observers (Allen et al. 2007; Littlefair and Buckley 2008; Scarpaci, Dayanthi, and Corkeron 2007; Wiley et al. 2008).

There are political and technical reasons why implementation of sustainability is so ineffective. The political reason is that many individuals and corporations gain from unsustainable actions. To maintain social licence to operate, while continuing business as usual, they claim sustainability by weakening its meaning. There are two approaches. The first is to add extra irrelevant components, 
so as to dilute the important ones, and then claim the proportions of components addressed. The second is to weaken the assessment criteria for each individual component. Both these approaches are used, for example, in ecocertification programs, in tourism as other sectors. These programs may use long checklists with no importance weightings, so that recycling office paper is given the same weight as conserving threatened species. They may also set unquantified criteria, so that installing a single low-wattage light globe counts as energy conservation, even if nothing else changes. They may also use vague terminology, as in studies analyzed by Juvan and Dolnicar (2016).

The technical reason is that it is difficult to define what constitutes sustainable behavior by an individual tourist, except under specific circumstances. Sustainability may be paraphrased as living so that the planet can continue to sustain human life for future human generations, under no worse conditions than the current human generation. Sustainability is thus a global scale concept, not an individual one. It requires actions by individuals, organizations, corporations, and nations, but it does not specify what those actions are. It is not specific to any sector, so it must be adapted to each, tourism included. The many "Agenda 21" documents, produced in the years following the first Rio Earth Summit, were attempts to do exactly that.

There are many circumstances, in tourism as in other industries, where it is clear which actions contribute to sustainability and which do not; but there are many others where it is far from straightforward, and the distinction depends on the frame of reference. A national park visitor who minimizes their environmental impacts through choice of activity, equipment, and behavior acts more sustainably than one who does not, within that local frame. If the low-impact visitor has traveled by air across the world to reach the park, however, and the high-impact visitor lives right next to it and walked there, then in that larger frame of reference, their global sustainability rankings may be different. How can we tell? Not through economics, because economics does not address how actions contribute or detract from planetary survival. Not through social factors such as equity, because the same applies. Money and human social structures influence progress toward or away from sustainability, but do not measure it.

Ultimately, we can only measure sustainability through changes in ecosystem structure and function at global scale. We do have some global measures, such as climate change, atmospheric and ocean pollution, and species extinctions. These are coarse measures, and only three out of many 
possibilities, but they provide a starting point. Any individual tourist who claims to be acting sustainably should not contribute to any of these. Any form of mechanized travel, however, contributes to climate change; any form of industrialized waste discharge contributes to air and water pollution; and any form of natural resource consumption contributes to species extinctions. This applies to everyone, not only tourists.

Tourists, like everyone else, can also make positive contributions to conservation. If these outweigh their individual negative environmental impacts, they could indeed achieve a net gain for sustainability. To make such an assessment requires a single ecological measure for both gains and losses. The most accurate is the change in probability of extinction of individual threatened species (Buckley, Morrison, and Castley 2016). Local conservation gains to individual species can outweigh threats to those same species through climate change associated with travel. This provides a theoretical mechanism to measure individual tourism sustainability. From a technical perspective, however, this approach is complex to apply, and requires a great deal of detail on travel patterns and the ecology of individual species.

There are several alternative approaches. We can select local-scale behaviors with straightforward and easily quantified consequences for sustainability, such as the choice between two actions with different environmental impacts, and measure how many tourists choose each option (Line, Hanks, and Miao 2018). Alternatively, we can adopt broader indicators of human behaviors, such as attitudes, intentions, motivations, ethical perspectives, or stated behaviors; but only where we can quantify how they are linked to global environmental change. The mechanism may be indirect, as long as it is unequivocal.

As one example, travel agents in French-speaking Switzerland follow personal beliefs to recommend particular African wildlife tourism operators to wealthy clients, based on those operators' contributions to conservation of threatened species and their habitats. In this case, the link between tourism marketing behavior and global sustainability is quite indirect, but all the intermediate steps have been tested: from agent recommendation, to client choice, to income for conservation tourism operators, to conservation actions, to increased probability of species survival (Mossaz, Buckley, and Castley 2015; Buckley and Mossaz 2016, 2018). Such links, however, depend on the details of individual cases. 
The contributions of the tourism sector to sustainability, either negative or positive, do indeed depend on the actions of individual tourists as well as tourism businesses and government agencies. It is indeed valuable to measure these contributions at the scale of individual tourists, but only if the specific parameters measured are actually relevant to sustainability. This requires rigor, to identify, test, and quantify the specific links by which a particular individual behavior, under a defined set of circumstances, contributes to sustainability at a planetary scale.

\section{References}

Allen, S. I., H. O. Smith, K. E. Waples, and R. Harcourt. 2007. "The Voluntary Code of Conduct for Dolphin Watching in Port Stephens, Australia: Is Self-Regulation an Effective Management Tool?" Journal of Cetacean Research and Management 9:159-66.

Buckley, R. C. 2012. "Sustainable Tourism: Research and Reality." Annals of Tourism Research 39:528-46.

Buckley, R. C., F. C. Morrison, and J. G. Castley. 2016. "Net Effects of Ecotourism on Threatened Species Survival." PLoS One 11:e0147988.

Buckley, R. C., and A. C. Mossaz. 2016. "Decision Making by Specialist Luxury Travel Agents." Tourism Management 55:133- 38.

Buckley, R. C., and A. C. Mossaz. 2018. "Private Conservation Funding from Wildlife Tourism Enterprises in Sub-Saharan Africa: Conservation Marketing Beliefs and Practices." Biological Conservation 218:57-63.

Gössling, S., and P. Peeters. 2015. “Assessing Tourism's Global Environmental Impact 1900-2050.” Journal of Sustainable Tourism 23:639-59.

Juvan, E., and S. Dolnicar. 2016. "Measuring Environmentally Sustainable Tourist Behaviour." Annals of Tourism Research 59:30-44.

Littlefair, C., and R. Buckley. 2008. "Interpretation Reduces Ecological Impacts of Visitors to World Heritage Site." Ambio 37:338-41.

Line, N. D., L. Hanks, and L. Miao. 2018. "Image Matters: Incentivizing Green Tourism Behavior." Journal of Travel Research 57:296-309.

Mossaz, A., R. C. Buckley, and J. G. Castley. 2015. "Ecotourism Contributions to Conservation of African Big Cats." Journal for Nature Conservation 28:112-18.

Scarpaci, C., N. Dayanthi, and P. J. Corkeron. 2003. "Compliance with Regulations by 'Swim-withDolphins' Operations in Port Phillip Bay, Victoria, Australia." Environmental Management 31:342-7.

Wiley, D. N., J. C. Moller, R. M. Pace, and C. Carlson. 2008. "Effectiveness of Voluntary Conservation Agreements: Case Study of Endangered Whales and Commercial Whale Watching." Conservation Biology 22:450-57. 